\title{
Factors Contributing to Medication Administration Errors and Barriers to Self- Reporting among Nurses: A Review of Literature
}

\author{
Aimable Nkurunziza ${ }^{1,2 *}$, Geldine Chironda ${ }^{1,3}$, Madeleine Mukeshimana ${ }^{1}$, Marie Claire Uwamahoro ${ }^{1}$, Marie Louise \\ Umwangange $^{1}$, Flavien Ngendahayo ${ }^{1}$

\begin{abstract}
${ }^{1}$ School of Nursing and Midwifery, College of Medicine and Health Sciences, University of Rwanda, Kigali, Rwanda
${ }^{2}$ Arthur Labatt Family School of Nursing, Faculty of Health Sciences, University of Western Ontario, London, Canada

${ }^{3}$ Rory Meyers College of Nursing, New York University, United States
\end{abstract}

*Corresponding author: Aimable Nkurunziza. School of Nursing and Midwifery, College of Medicine and Health Sciences, University of Rwanda, Remera Campus, KG 11 Ave, 47, Kigali, Rwanda.Email:aimableinter@gmail.com

\begin{abstract}
Background

Medication Administration Errors (MAEs) are common among nurses and can threaten all patients' outcomes. Furthermore, MAEs are the leading cause of incidents in patient safety records worldwide.

Objective

To review the types of medication administration errors, factors contributing to MAEs and barriers to self-reporting among nurses.

Methods

A review of the literature was done and included original articles and grey literature from January 2011 until July 2017. An advanced search was done in Medline, HINARI, PubMed, CINAHL, Science direct, Google Scholar and gray literature using a Boolean combination of different keywords such as "medication administration error", "adverse drugs reactions", barriers and "self-reporting".

Results

257 articles were eligible for review but only27 articles met the inclusion criteria. Types of MAEs mainly focused on seven rights (right patient, right drug, right dose, right time, right route, right reason and right documentation). With regards to the types of MAEs, the wrong time was most prevalent in this study. Being overworked was the main factor contributing to medication administration errors. The barriers to self-reporting during MAEs were dominated by fear of disciplinary action. Nurses' characteristics such as age, experience, education, variations in how errors are defined and organizational factors such as power, distance and lack of reporting policies were found to be barriers to self-reporting. In addition to that, others were identified.

\section{Conclusion}

Globally, MAEs remain a pervasive problem among nurses. Contributing factors range from individual to organizational factors, and barriers to self-report are due to fear of legal action and punishment. There is a need to devise measures that will prevent these errors and to promote positive clinical outcomes of patients in healthcare settings.

Rwanda J Med Health Sci 2019;2(3):294-303.
\end{abstract}

Keywords: contributing factors, medication administration errors, barriers, self-reporting, nurse.

\section{Introduction}

Medication administration error (MAE) is any preventable act that contributes to the failure of proper medication use or causes problems for the patient while in the care of a healthcare professional, clients, or consumer.[1] MAEs happen at different stages in the medication use process, including prescribing, provision and administration.[2,3] Such errors may be associated with healthcare professionals' practices or techniques, products or drugs and systems, including prescription, miscommunication, labeling, packaging and nomenclature, assembling, distributing and administration.[1]

MAE is a global challenge and $18.7 \%-56 \%$ of hospitalized patients face medication administration errors. [4] A study done in Australia found that $60 \%$ to $80 \%$ of patients faced MAEs and omission errors accounted for between $40 \%$ to $60 \%$. [5] In Nigeria, the prevalence of MAEs among nurses was $64 \%$, whilst $44 \%$ did not know of the existence of a reporting system, and a minority of $30 \%$ reported MAEs among pediatric nurses. [6]

MAEs impact negatively on patients in terms of morbidity, mortality, Adverse Drugs Reactions (ADRs), and increased the length of hospitalization. In the 
report called "To Err is Human: Building a Safer Health System" published by the Institute of Medicine (IOM) located in the United States of America confirmed the fact that each year MAEs cause more than 7,000 deaths. [3] Additionally, the National Coordinating Council for Medication Error Reporting and Prevention of Medication Errors, USA, also revealed that medication errors cause injury to at least 1.5 million people, and to treat those injuries costs approximately 3.5 billion dollars per year.[7]

MAEs are common among nurses and can threaten all patients' outcomes, but mainly the pediatric population $[8,9]$, due to their physiological and developmental needs.[10] The available literature reported that nurses are reported to commit more MAEs as compared to other health care professionals like medicine and anesthesia.[11]

The first step to reduce MAEs among nurses is to identify the types of commonly occurring errors, [12, 13] assess the factors contributing to those errors, as well as barriers to self-reporting, and to set up appropriate preventive measures.[14, 15] However, there is no documented summative review of literature that identifies types of MAEs and factors contributing to medication administration errors, as well as barriers to self-reporting among nurses at the same time. Therefore, this current review aims to integrate studies that were done in relation to this topic and to identify the types of medication administration errors, factors contributing to MAEs and barriers to self-reporting. The identification of the aforementioned attributes will aid in implementing measures for the prevention of any MAEs and improving the management of patients in healthcare settings.

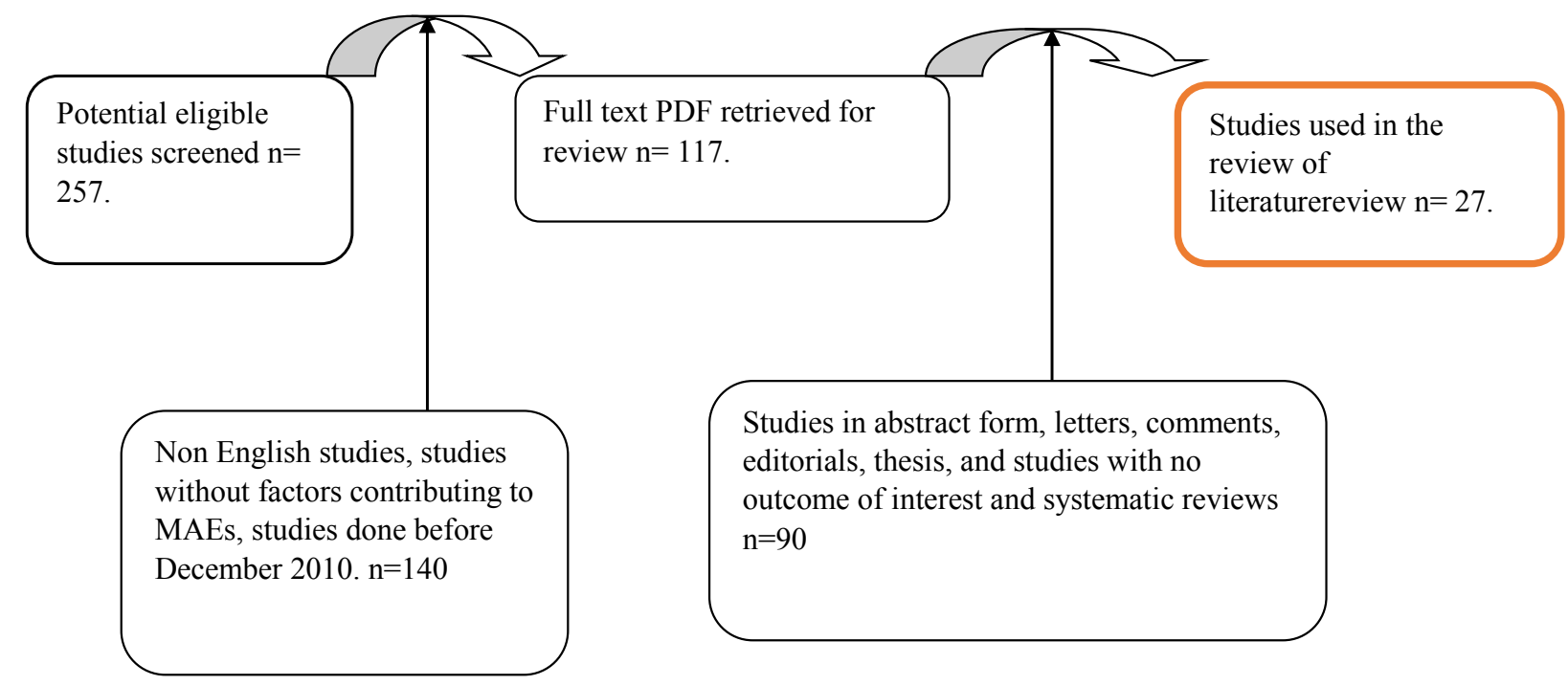

\section{Methodology}

A review of the literature was conducted and included original articles and grey literature from January 2011 until July 2017. An advanced search was done in Medline, HINARI, PubMed, CINAHL, Siencedirect, Google Scholar and gray literature using a Boolean combination of different keywords such as medication administration errors' AND 'factors' OR 'self-reporting' AND 'nurses' AND 'barriers'. For a comprehensive search, the following alternative words were used 'contributing factors to medication administration errors', 'medication errors', 'adverse drugs reactions' and 'barriers to self- reporting'. Both quantitative and qualitative studies written in English were included in this review to identify the factors contributing to MAEs and barriers to self-reporting among nurses. Comments, editorials, systematic reviews and studies with no outcome of interest were excluded from this review of the literature. Three authors did the first search and selection, and two other authors checked the articles and agreed on the included articles. All 27 articles were reported in the matrix which included authors, title and journal, study type, study design study population, and sample size (Table 1).

\section{Data analysis}

Descriptive analysis was used to identify the frequencies of MAEs, factors contributing to MAEs and barriers to self-reporting after committing an error. Tables were used.

\section{Results}

\section{Studies included}

Initially, 257 studies (Figure 1) were obtained from the research. Following inclusion and exclusion criteria, only 27 articles (Table 1) were considered including 26 quantitative studies and 1 qualitative study.

Figure 1. Diagram of studies selection flow 
Table 1. Details of 27 articles reviewed

\begin{tabular}{llll}
\hline Author/Year/Title Journal & $\begin{array}{l}\text { Research Country } \\
\text { approach and } \\
\text { design }\end{array}$ & $\begin{array}{l}\text { Study } \\
\text { popu- } \\
\text { lation }\end{array}$ \\
\hline
\end{tabular}

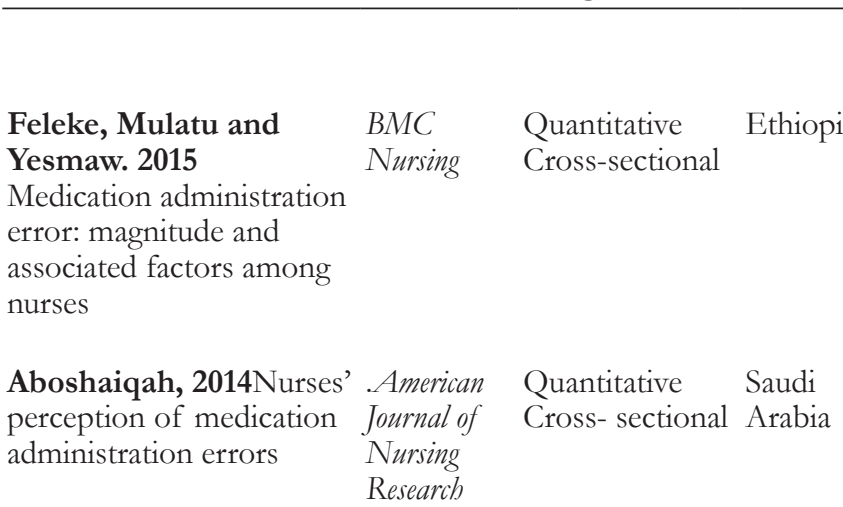
$\begin{array}{ll}\text { Miladinia, Zarea, Baraz International Quantitative Iran } \\ \text { and Nouri, 2016. } & \text { Journal of Cross- sectional } \\ \text { Pediatric nurses } & \text { Pediatric }\end{array}$

Medication Error :

the Self-reporting of

Frequency, Types and

Causes

Oshikoya et al., 2013

MAEs among pediatric nurses in Lagos public hospitals : An opinion survey

\section{Types of MAEs}

Documentation, technique and time

309

Time, technique, dose, medication without physician order and route

(1)




\begin{tabular}{|c|c|c|c|c|c|c|}
\hline $\begin{array}{l}\text { Rahimi et al., } 205 \\
\text { Factors influencing } \\
\text { medication errors } \\
\text { according to nurses' } \\
\text { decisions to do self-report }\end{array}$ & $\begin{array}{l}\text { Int J } \\
\text { Basic Clin } \\
\text { Pharmacol. }\end{array}$ & $\begin{array}{l}\text { Quantitative } \\
\text { Analytical }\end{array}$ & Iran & 100 & $\begin{array}{l}\text { Patient, } \\
\text { dose, time, } \\
\text { medication }\end{array}$ & $\begin{array}{l}\text { Workload, unit } \\
\text { and nurse- } \\
\text { physician } \\
\text { relationship }\end{array}$ \\
\hline
\end{tabular}

\section{Zakharov, Tomas and \\ Pelclova, 2012. \\ Medication errors; an enduring problem for children and elderly patients}

Ojerinde and Adejum 2014.

Factors associated $\begin{array}{lll}\text { Ups JMed } & \text { Quantitative } & \text { Czech } \\ \text { Sci. } & \text { Retrospective } & \text { Republic }\end{array}$

with medication errors among health workers In University College Hospital, Nigeria

\section{Khammamia and}

Rvangard, 2015.

Medical errors and

\section{Malays J}

Iran

Med Sci

barriers to reporting in ten hospitals in Southern Iran.

Vilela and Jerico, 2015 Medication errors : management of the medication error indicator toward a more safety nursing practice

Johari et al., 2015

Medication errors among nurses in Government Hospital

Journal of

Nigeria

333

Dose and Health

Science Descriptive

Cross-sectional

J Nurs UFPE line

Quantitative

Descriptive and

Exploratory

(Retrospective)

90

Journal of

Nursing and Health

Science
Quantitative

Quantitative

International Quantitative

Iran

Tabatabaee et al., 2014

Barriers to medication error reporting from nurses' perspective: a Journal of Cross-sectional Hospital

Research

private

hospital survey.

\section{Yung et al., 2016}

Nurses' attitudes and perceived barriers to the reporting of medication administration errors.

\section{Saleh Alduais et al., 2014 Journal of}

Barriers and strategies of Nursing

reporting medical errors in and Health

public hospitals in Riyadh Science

city: a survey-study.
Bahadori et al., 2014

The factors affecting the refusal of reporting on medication errors from the nurses' viewpoints:

a case study in a hospital in

Iran.

Abou Hashish and ElBialy, 2013.

Nurses' perceptions of safety climate and barriers to report medication errors
ISRN Nurs Quantitative Iran 100

Cross- sectional
Quantitative Taiwan 306

Cross-sectional and route
Dose, drug
Sound-like drugs - $\begin{array}{ll}\text { Workload, } & \text { Fear of } \\ \text { interruptions, } & \text { punishments } \\ \text { drug labeling and } & \\ \text { packaging } & \end{array}$

Largest hospital, Work experience internal wards, individual and organizational

Lack of attention and workload
Omission, patient and time
Personal neglect, heavy workload, new staff and complicated orders.
Fear of legal involvement, fear of losing a job, and fear of the consequences

Fear of the negative consequences
Quantitative Saudi Survey Arabia approach
Blame, punishment, filling in the form; poor knowledge

Managerial factors, process of reporting and fear of the consequences of reporting.

Disagreement over what a medication error is and its definition, and power distance. 


\begin{tabular}{lllll}
\hline Mohammad, Aljasser & British & Quantitative Saudi & 300 & Administrative \\
and Sasidhar, 2016. & Journal of & Cross- sectional Arabia & & response and fear. \\
Barriers to Reporting & Economics, & & & \\
Medication Administration Management & & & \\
Errors among Nurses in & $\&$ Trade & & \\
an Accredited Hospital in & & & & \\
Saudi Arabia. & &
\end{tabular}

$\begin{array}{lllll}\begin{array}{l}\text { Hardmeier et al., 2014 } \\ \text { Pediatric Administration } \\ \text { Errors and Workflow }\end{array} & \begin{array}{l}\text { J Healthc } \\ \text { Qual }\end{array} & \begin{array}{l}\text { Quantitative } \\ \text { Observational }\end{array} & \begin{array}{l}\text { California, 300 } \\ \text { USA }\end{array} & \begin{array}{l}\text { Route, } \\ \text { technique, time } \\ \text { and omission }\end{array}\end{array}$

Following Implementation of a Bar Code Medication

Administration System.

\begin{abstract}
Sears and Goodman, 2012.

Risk Factors for Increased

Severity of Paediatric

Medication Administration

Errors.
\end{abstract}

Abdel-Latif, 2016

Knowledge of healthcare professionals about medication errors in hospitals $\begin{array}{ll}\text { Healthc } & \text { Quantitative Canada } \\ \text { Plicy } & \text { Observational } \\ & \\ \text { J Basic Clin } & \text { Quantitative Saudi } \\ \text { Pharma } & \text { Cross- sectional Arabia }\end{array}$
J Nurs Heal Quantitative Saudi

Sci Cross- sectional Arabia and Nabila, 2013

Nurses' experiences toward Perception of

MAEs Reporting
Zamanzadeh et al., 2012 J Caring Sci. Quantitative

Medication Error

Reporting Rate and its

Barriers and Facilitators

among Nurses.

You et al., 2015

Perceptions regarding

MAEs among hospital

staff nurses of South

Korea.

Samsiah et al., 2015Perceptions and

Attitudes towards

Medication Error

Reporting in Primary Care

Clinics : A Qualitative

Study in Malaysia.
Medication package, system, documentationtranscription, physician-nurse and pharmacy reasons.

training, teaching a student and offservice patient.
Prescribing

and

administration

errors
Int Jual Quantitative South

Heal Care. Cross- sectional Korea
253

Descriptive

Patient, dose and drug
No clear mechanism available for reporting and poor knowledge about selfreporting.

Fear reasons, administrative reasons, disagreements over time error definition reasons.

Blaming, negative consequences of reporting errors, and fear of reprimand and punishment.

\section{Workload and Blaming and} administering having too drugs with similar much emphasis names or labels on MAEs as a measure of nursing care quality.

$$
\begin{array}{llll}
\text { PLoS One } & \text { Qualitative } & \text { Malaysia } & 31 \\
& \text { Focus groups } & &
\end{array}
$$

The nature of the error, reporting system, organizational factors, provider factors, reporter's burden and benefit of reporting.

Physician orders are not clear, inadequate staff and absence of pharmacists
Fear, administrative process and lack of a clear definition of an error. 


\section{Types of medication administration errors}

About 9 articles reported different types of medication administrations errors. The most reported medication administration error in this review was incorrect time. $[5,11-13,15-19]$ The second error was the wrong dosage or wrong dosage calculation which was reported by 7 articles.[5, 9, 11, 15, 20-22] Other types of errors identified were incorrect medication, $[9,20-22]$ incorrect route, $[12,15,18,21]$ incorrect patient, $[5,12,21,22]$ error in technique, $[16,18,23]$ omitting a drug due to drug availability $[17,18]$ and administration of a drug which is not prescribed.[13, 15] There was another type of error that was less apparent which is documentation.[16]
Table 2.Types of medication errors

\begin{tabular}{lc}
\hline Types of error & Number of articles \\
\hline Incorrect time & 9 \\
Incorrect dosage & 7 \\
Incorrect technique & 3 \\
Incorrect medication & 4 \\
Incorrect route & 4 \\
Incorrect patient & 4 \\
Omission & 2 \\
Documentation & 1 \\
Administration of a drug & 2 \\
which is not prescribed & \\
\hline
\end{tabular}

Factors contributing to medication administration errors Factors contributing to MAEs evident in this review can be categorized as follows; nurse-related factors, physician-related factors, nurse-physician related factors and organizational factors.

Table 3. Factors contributing to medication administration errors

\begin{tabular}{lc}
\hline Factors & Number of articles \\
\hline Nurse factors & 1 \\
\hline Age & 1 \\
Work experience & 2 \\
Poor medication knowledge & 1 \\
Poor calculation skills & 1 \\
No double checking of drugs & 2 \\
Inattention, negligence & 1 \\
New staff & 4 \\
Medication package/similarity & 1 \\
Insufficient training & 1 \\
Teaching a student & \\
Physician factors & 5 \\
Physicians change orders & \\
Nurse-physician factors & 3 \\
Poor relationship between nurses and physicians & \\
Organizational factors & 1 \\
Nurse patients' ratio & 2 \\
Shift & 8 \\
Workload & 2 \\
Interruptions & 1 \\
Unit & 1 \\
Pharmacy reasons & 2 \\
Individual factors in the view point of manager & \\
Patient factors & \\
Patient age & 1 \\
Off-service patient & 1 \\
\hline
\end{tabular}

\section{Nurse-related factors}

In this review, nurse related factors were factors such as demographic characteristics, including age,[16] work experience,[16] being new nurse,[24] individual knowledge and skills about a medication, $[15,20]$ and dosage calculation.[20] Other nurse related factors are linked to their daily work, such as lack of double checking of drugs, [11] inattention or negligence,[17,
24] how a medication is packaged/visible, [9, 21, 22, 25] insufficient training and teaching a student.[19]

\section{Physician-related factors}

Change of medication orders which sometimes are not clear were mentioned as factors related to MAEs in 5 articles.[11, 15, 24-26] 


\section{Nurse-physician related factors}

Poor communication between nurses and physicians $[5,15,25]$ is the only nurse-physician related factor contributing to medication administration error reported in this review.

\section{Organizational factors}

There were many errors related to organizations. Being overworked was most prominent. [5, 9, 11, 17, 19, 22, $24,27]$ Nurse to patient ratio [16] was another factor where nurses claimed to care for more patients due to patient overcrowding. Nurses also reported that the night shift $[16,27]$ was contributing to medication administration errors. Medication errors also vary depending on the unit or the department. [14] They were also other organizational factors such as interruptions during medication administration, $[9,16]$ pharmacy procedures [25] and viewpoint of the manager regarding administration errors. [13, 14$]$

\section{Patient-related factors}

The factor reported here was age,[16] where errors in administration are commonly found in the pediatric department and off-service patient.[19]

\section{Barriers to self-reporting}

Regarding barriers to self-reporting evident in this review, they can be categorized as follows; reporting outcomes associated barriers, organizational barriers, nurse related factors and other various factors.

\section{Table 4. Barriers to self-reporting}

\begin{tabular}{ll}
\hline Self-reporting barriers & Number of articles \\
\hline Self-reporting outcomes & 13 \\
Fear of negative consequences & 4 \\
Blame & 1 \\
Organizational factors & 5 \\
Lack of policies to report & 4 \\
Managerial/administrative factors & 1 \\
Process of reporting & 1 \\
having too much emphasis on MAEs as a measure of nursing care quality & \\
Power distance & 1 \\
Nurse factors & 1 \\
Experience & 4 \\
Disagreement on what medication error is and its definition & \\
Other & 1 \\
Nature of the error & \\
\hline
\end{tabular}

\section{Self-reporting outcomes}

In this review, fear of negative consequences such us punishment and losing a job after self-reporting $[9,11$, $32-34,12,13,25,26,28-31]$ and fear of blames $[13,22,30$, $33]$ were reported to be barriers to self-reporting.

\section{Organizational factors}

Lack of policies in different institutions,[11] managerial/ administrative factors, $[12,25,26,31,32]$ unclear or long process to report, $[23,30,31,34]$ such as having too much emphasis on MAEs as a measure of nursing care quality [22]were some of the factors that were reported in this review. Power distance,[35] the way nurses view and accept an unequal sharing of power from managers was another contributing factor.

\section{Nurse-related factors}

Disagreement of what medication error is and its definition[12,25,26,35]was reported as a barrier. Nurses who had less job experience were likely to report compared to those who have more experience.[14] It was also observed that nurses' level of education is a barrier to self-reporting,[12] with a bachelor's degree exhibiting higher perception levels of barriers in reporting MAEs

\section{The nature of the error}

The nature of the error was found to be a barrier to self-reporting[34] among nurses. But in the end, nurses agreed that actual errors and near misses should be reported as this will portray a complete picture of all sources of risks and events that are harmful to patients. 


\section{Discussion}

This literature review found 27 articles reporting the types of errors in the administration of medications, factors contributing to those errors and barriers to self-reporting when errors are committed. This review has an added value as it aids the reader in identifying the types of errors in the administration of medications, factors contributing to those errors and barriers to self-reporting at the same time. The previous reviews were only focusing on one aspect; either on errors in the administration of medication, [36] factors contributing to those errors,[37] or on self-reporting.[38]

Medication administration is the last and key step in the medication process, and if not done correctly, it can harm patients. Identifying administration errors is very important to determine early interventions. The literature showed that there are many types of administration errors.[39] The articles in this review identified various types of errors and are mainly focusing medication administration rights. The incorrect time was the most prevalent in this study. However, there is an inconsistency in previous reviews [36, 40] about the most commonly occurring administration errors probably due to different methods used in the different studies.

Factors of MAEs found in this review were wideranging. Being overworked was the most prevalent. The studies revealed that it is impossible to expect nurses to avoid MAEs when they themselves are stressed out and fatigued.[2,4,5,8,13,24] The issue of overworking among nurses was reported in other reviews[41] and revealed that overworked nurses almost seem to be the norm rather than the exception, but this negatively impacts patient safety. Nurses are human beings and have to get sufficient time to rest to ensure safe drug administration. The other commonly contributing factors were unclear orders from physicians and other organizational factors. The findings are reported in other previous reviews. [16,36,42]

Nurses have the professional, legal and ethical responsibility to recognize and report errors that occur during medication administration.[12] However, nurses may be reluctant to report for various reasons. The barriers to self-reporting during medication administration reported in this review were dominated by fear of disciplinary actions. Nurses' characteristics such as age, experience, education, variations in how errors are defined were found to be additional barriers. In addition to that, other organizational factors such as power distance and lack of reporting policies were identified. These findings are supported by other reviews and studies about barriers to self-reporting but with different ranking order.[12, 22, 43]

\section{Limitations of the review}

There was only one qualitative study identifying factors contributing to medication errors and barriers to selfreporting. The search was limited to studies from 2011 to 2017. More contributing factors to medication errors and barriers to self-reporting might have been missed from studies dated 2010 and earlier. Fewer studies were identified from African countries. Due to different geographical locations and working conditions among nurses, medication errors and barriers to self-reporting cannot be generalized to Africa.

\section{Conclusion}

In conclusion, incorrect time was commonly found in literature as a MAE. Workload was the common contributing factor to the MAEs and fear of negative consequences after self-reporting was the common barrier to self-report after committing an error. Most of the researches that have been conducted to rule out the factors contributing to MAEs and barriers to selfreporting have urged that the prevention be based first on the identification of those factors and on finding a way forward. They have also proposed some strategies that are not negative but encourage nurses to self-report, such as appreciation in the nurses meeting, providing some awards, etc. These measures also prevent the future occurrence of MAEs and increase the level of reporting.

\section{Authors' contribution}

The authors contributed in this manuscript as follows: AN, GC and MM developed the concept and study design. MC. U, ML. U and F N did the literature search and data analysis. All authors discussed the results and commented on the manuscript. All authors participated in responding to the reviewers' comments and approving the final version.

\section{Conflict of interest}

The authors declare that they have no conflict of interest.

This article is published open access under the Creative Commons Attribution-NonCommercial NoDerivatives (CC BY-NC-ND4.0). People can copy and redistribute the article only for noncommercial purposes and as long as they give appropriate credit to the authors. They cannot distribute any modified material obtained by remixing, transforming or building upon this article. See https://creativecommons.org/ licenses/by-nc-nd/4.0/ 


\section{References}

1. Stratton KM, Blegen MA, Vaughn T. Reporting of Medication Errors by Pediatric Nurses. J Pediatr Nurs. 2004;19:385-92.

2. Berdot S, Sabatier B, Gillaizeau F, Caruba T, Prognon P. Evaluation of drug administration errors in a teaching hospital. BMC Health Serv Res. BioMed Central Ltd; 2012;12:60.

3. Institute of Medicine. Preventing Medication Errors. 2006;

4. Tshiamo WB, Kgositau M, Ntsayagae E, Sabone MB. The role of nursing education in preventing medication errors in Botswana. Int J Africa Nurs Sci. Elsevier Ltd; 2015;3:18-23.

5. Rahimi F, Rezaei S, Baghaei R, Feizi A. Factors influencing medication errors according to nurses' decisions to do self-report. Int J Basic Clin Pharmacol. 2015;4:130.

6. Abdar ZE, Tajaddini H, Bazrafshan A, Khoshab H, Tavan A. Registered Nurses Perception of Medication Errors: A Cross Sectional Study in Southeast of Iran. Int J Nurs Educ. 2014;6:19-23.

7. National Coordinating Council for Medication Error Reporting and Prevention. Medication Errors. 2016. p. 1.

8. Zakharov S, Tomas N, Pelclova D. Medication errors - an enduring problem for children and elderly patients. Ups J Med Sci. 2012;309-17.

9. Ojerinde AC, Adejumo PO. Factors Associated With Medication Errors Among Health Workers In University College Hospital, Nigeria. IOSR J Nurs Heal Sci. 2014;3:22-33.

10. Alomar MJ. Factors affecting the development of adverse drug reactions ( Review article). Saudi Pharm J. King Saud University; 2014;22:83-94.

11. Oshikoya KA, Oreagba IA, Ogunleye OO, Senbanjo IO, MacEbong GL, Olayemi SO. Medication administration errors among paediatric nurses in Lagos public hospitals: An opinion survey. Int J Risk Saf Med. 2013;25:67-78.

12. Biffu BB, Dachew BA, Tiruneh BT, Beshah DT. Medication administration error reporting and associated factors among nurses working at the University of Gondar referral hospital, Northwest Ethiopia, 2015. BMC Nurs. BMC Nursing; 2016;15:1-7.

13. Ebrahimipour H, Hosseini SE, Haghighi H, Tabatabaee SS. Evaluation of Medication Errors by Nurses in Hospitals Affiliated with Mashhad University of Medical Sciences, Mashhad, Iran.
Patient Saf Qual Improv J. 2016;1:400-4.

14. Khammarnia M, Ravangard R. Medical Errors and Barriers to Reporting in Ten Hospitals in Southern Iran. Malays J Med Sci. 2015;22:57-63.

15. Aboshaiqah AE. Nurses, Perception of Medication Administration Errors. Am J Nurs Res. 2014;2:63-7.

16. Feleke SA, Mulatu MA, Yesmaw YS. Medication administration error: Magnitude and associated factors among nurses in Ethiopia. BMC Nurs. BMC Nursing; 2015;14:1-8.

17. Prado R, Vilela B, De M, Jericó C. Erro De Medicação: Gestão Do Indicador Para Uma Prática Mais Segura Medication Errors: Management of the Medication Error Indicator Toward a More Safety Nursing Practice Error De Medicamento: Gestion Del Indicador Para Una Prática Más Segura. 2015;10.

18. Hardmeier A, Tsourounis C, Moore M, Abbott WE, Guglielmo BJ. Pediatric Medication Administration Errors and Workflow Following Implementation of a Bar Code Medication Administration System. J Healthc Qual. 2014;36:54-63.

19. Sears K, Goodman WM. Risk factors for increased severity of paediatric medication administration errors. Healthc Policy. 2012;8:109-26.

20. Miladinia M, Zarea K, Baraz S, Mousavi Nouri E, Pishgooie AH, Gholamzadeh Baeis M. Pediatric Nurses' Medication Error: the Self-reporting of Frequency, Types and Causes. Int J Pediatr. 2016;4:1439-44.

21. Zakharov S, Tomas N, Pelclova D. Medication errorsan enduring problem for children and elderly patients. Ups J Med Sci. 2012;117:309_ 17.

22. You MA, Choe MH, Park GO, Kim SH, Son YJ. Perceptions regarding medication administration errors among hospital staff nurses of South Korea. Int J Qual Heal Care. 2015;27:276-83.

23. Abdel-Latif MMM. Knowledge of healthcare professionals about medication errors in hospitals. J Basic Clin Pharma 2016;787-92. 2016;7:87-92.

24. Hariati Johari HJ. Medication Errors Among Nurses in Government Hospital. IOSR J Nurs Heal Sci. 2013;1:18-23.

25. Al-Youssif AS, Mohamed KL, Nabila MS. Nurses 'Experiences toward Perception of Medication Administration Errors Reporting. J Nurs Heal Sci. 2013;1:56-70. 
26. Abdullah HAD, Sameen YF. Barriers that Preventing the Nursing Staff from Reporting Medication Errors in Kirkuk City Hospitals. Kufa J Nurs Sci. 2017;7:145-56.

27. Abdar ZE, Tajaddini H, Bazrafshan A, Khoshab H, Tavan A, Afsharpoor G, et al. Registered Nurses Perception of Medication Errors: A Cross Sectional Study in Southeast of Iran. Int J Nurs Educ. 2014;6:19.

28. Tabatabaee SS, Kalhor R, Nejatzadegan Z, Jahromi KV, Sharifi T. Barriers to Medication Error Reporting from Nurses' Perspective : A Private Open Access. Int J Hosp Res. 2014;3:97102.

29. Yung H, Yu S, Chu C, Hou I, Ang F. Nurses' attitudes and perceived barriers to the reporting of medication administration errors. J Nurs Manag. 2016;24:580-8.

30. Saleh Alduais AM, Mogali S, Al Shabrain B, Al Enazi A, Al-awad F. Barriers and strategies of reporting medical errors in public hospitals in Riyadh city: A survey-study. IOSR J Nurs Heal Sci. 2014;3:72-85.

31. Bahadori M, Ravangard R, Aghili A, Sadeghifar J, Gharsi Manshadi M, Smaeilnejad J. The Factors Affecting the Refusal of Reporting on Medication Errors from the Nurses' Viewpoints: A Case Study in a Hospital in Iran. ISRN Nurs. 2013;2013:1-5.

32. Mohammad AZ, Aljasser IA, Sasidhar B. Barriers to Reporting Medication Administration Errors among Nurses in an Accredited Hospital in Saudi Arabia. Br J Econ Manag Trade. 2016;11:1-13.

33. Zamanzadeh V, Bayazidi S, Zarezadeh Y, Parvan K. Medication Error Reporting Rate and its Barriers and Facilitators among Nurses. J caring Sci. 2012;1:231-6.

34. Samsiah A, Othman N, Jamshed S, Hassali MA. Perceptions and attitudes towards medication error reporting in primary care clinics: A qualitative study in Malaysia. PLoS One. 2016;11:1-19.
35. Abou Hashish EA, El-Bialy GG. Nurses' perceptions of safety climate and barriers to report medication errors. Life Sci. J. 2013. p. 2160-8.

36. Berdot S, Gillaizeau F, Caruba T, Prognon P, Durieux P. Drug Administration Errors in Hospital Inpatients : A Systematic Review. PLoS Med. 2013;8:1-11.

37. Keers RN, Williams SD, Cooke J, Ashcroft DM. Causes of Medication Administration Errors in Hospitals : a Systematic Review of Quantitative and Qualitative Evidence. Drug Saf. 2013;36:1045-67.

38. Khowaja K, Nizar R, Merchant RJ, Dias J, Bustamante-Gavino I, Malik A. ORIGINAL RESEARCH A systematic approach of tracking and reporting medication errors at a tertiary care university. Ther Clin Risk Manag 20084(4). 2008;4:673-9.

39. Lisby M. How are medication errors defined? A systematic literature review of definitions and characteristics. nternational J Qual Heal Care. 2010;22:507-18.

40. Parand A, Garfield S, Vincent C, Franklin BD. Carers' Medication Administration Errors in the Domiciliary Setting : A Systematic Review. PLoS One. 2016;11:e0167204.

41. Alomari A, Wilson V, Davidson PM, Lewis J. Families, nurses and organisations contributing factors to medication administration error in paediatrics : a literature review. Int Pract Dev J. 2015;5:[7].

42. Ahmed Ameer, Dhillon S, Peters MJ, Ghaleb M. Systematic literature review of hospital medication administration errors in children. Integr Pharm Res Pract. 2015;4:153-65.

43. Ahmadizar F, Soleymani F, Abdollahi M. Study of Drug-Drug Interactions in Prescriptions of General Practitioners and Specialists in Iran 2007-2009. Iran J Pharm Res. 2011;10:921-31. 